\title{
EPS8 Peptide-specific Dendritic Cells
}

National Cancer Institute

\section{Source}

National Cancer Institute. EPS8 Peptide-specific Dendritic Cells. NCI Thesaurus. Code C148518.

A preparation of dendritic cells (DCs) pulsed with peptides derived from epidermal growth factor receptor (EGFR) pathway substrate 8 (EPS8), with potential immunostimulating and antineoplastic activities. Upon administration of the EPS8 peptide-specific DCs, the immune system is exposed to the EPS8 antigens. This results in the induction of a specific cytotoxic T-lymphocyte (CTL) response against EPS8-expressing tumor cells and tumor cell lysis. EPS8, a tumor-associated antigen (TAA), is overexpressed in a variety of tumor cell types but rarely in normal tissues. As a substrate for the EGFR kinase, it plays a key role in tumor progression through the EGFR-dependent pathway. Its expression is correlated with a poor prognosis. 